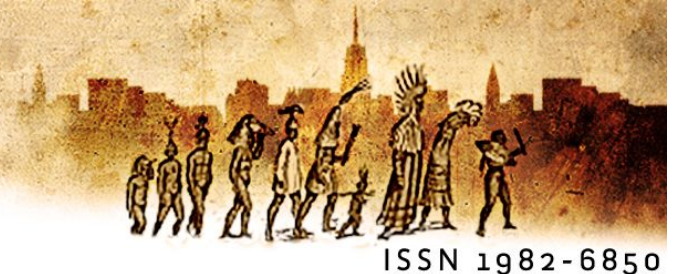

\title{
"Cara a cara com o gênero": o conceito de gênero de texto e o desenvolvimento profissional de professores em formação continuada
}

Anderson Carnin' (UNISINOS)

\begin{abstract}
Resumo: Este artigo discute como o trabalho de ensino de uma professora é afetado pelo seu desenvolvimento profissional, especialmente pela transformação do conceito de gênero de texto em instrumento psicológico que passa a (re)orientar seu agir. Os aportes teóricos que nortearam a pesquisa são oriundos do quadro interacionista sociodiscursivo (BRONCKART, 2006; 2008; 2011; 2013; FRIEDRICH, 2012), aliados aos estudos da didática da escrita (REUTER, 2013; GUIMARÃES; $\mathrm{KERSCH}, 2012 ; 2014 ; 2015)$. As análises empreendidas debruçam-se sobre a escrita praxiológica do professor em formação continuada, procurando evidenciar, a partir dessa escrita, índices de desenvolvimento profissional do professor.

Palavras-chave: gênero de texto; projeto didático de gênero; escrita praxiológica; desenvolvimento profissional; interacionismo sociodiscursivo.
\end{abstract}

\begin{abstract}
This paper discusses how the educational work of a teacher is affected by their professional development, especially the transformation of the text genre concept in psychological instrument that (re) guides his actions. The theoretical framework that guided the research come from the socio-discursive interactionism framework (BRONCKART, 2006; 2008; 2011; 2013; FRIEDRICH, 2012), allied to writing didactic studies (REUTER, 2013; GUIMARÃES; KERSCH, 2012; 2014; 2015). The analyzes undertaken are working on the praxiological writing teacher in continuing education, looking for evidence, from this writing, professional development indices teacher.
\end{abstract}

Keywords: text genre; praxiological writing; genre didactical projects; professional development; socio-discursive interactionism.

\section{Introdução}

Este artigo dedica-se a refletir sobre o desenvolvimento profissional de uma professora de Língua Portuguesa à luz do Interacionismo Sociodiscursivo. Mais especificamente, sobre como o trabalho didático desta professora é afetado pelo seu desenvolvimento profissional, especialmente pela transformação de um conceito científico em instrumento psicológico que passa a (re)orientar seu agir. Isso tudo, evidentemente, dá-se em um contexto bastante específico: analisamos a escrita praxiológica de uma professora que, participando de uma 
formação continuada durante os anos de 2012 a 2014, conheceu (e se apropriou de) um novo dispositivo de ensino e, a partir dele, passou a incorporar em seu trabalho (didático) o conceito de gênero de texto enquanto instrumento psicológico.

Tendo a noção de projeto didático de gênero - PDG - (GUIMARÃES; KERSCH, 2012; 2014; 2015) como âncora da pesquisa, investigamos como o conceito de gênero de texto evidenciado na transposição didática efetuada pela professora em formação continuada ao elaborar um PDG pode nos fornecer acesso a índices de seu desenvolvimento profissional. Tomado como instrumento psicológico, o conceito de gênero de texto permitiu lançar um outro olhar ao trabalho do professor e à sua formação e desenvolvimento profissional. Sobre isso, discorremos mais detidamente na(s) seção(ões) que segue(m).

\section{O trabalho docente e o conceito de gênero de texto enquanto instrumento psicológico}

Na esteira da discussão efetivada por Machado e Lousada (2010), em que o conceito de gênero de texto enquanto instrumento psicológico é posto em evidência, ressaltamos que a compreensão do conceito de instrumento em termos de trabalho do professor (e também em um contexto mais amplo) precisa ser aprofundada. Segundo Machado e Lousada (2010), é necessário construir uma conceituação psicológica da noção de instrumento que supere a compreensão do senso comum de que instrumento é, apenas, um objeto material existente fora do sujeito. Salientam as autoras que essa concepção de instrumento como objeto físico concreto não é suficiente para a análise da ação desenvolvida pelos participantes de uma ação.

No texto em questão, Machado e Lousada (2010) apontam, ainda, para a necessidade de que se investigue a relação entre a proposição por elas defendida (gênero de texto enquanto instrumento psicológico) e a questão do ensino de gêneros e o possível desenvolvimento do professor. Advogam também a necessidade de pesquisas que desenvolvam essa hipótese e confirmem sua validade. À semelhança das autoras, concordamos com essa hipótese e trabalhamos para que esse pensamento seja mais bem esclarecido e definido. Para isso, (re)tomamos, com Machado e Lousada (2010), o conceito de gênero de texto em uma perspectiva da psicologia vigotskiana, almejando inserir essa discussão já proposta pelas autoras no escopo da análise do trabalho do professor em formação continuada. 


\subsection{Gênero de texto enquanto instrumento psicológico}

A partir de uma grande pesquisa acerca do funcionamento dos textos/discursos, Jean-Paul Bronckart propôs um conceito de gênero de texto muito próximo do conceito bakhtiniano de gênero do discurso. Bronckart (1999, p. 101-102) define, à semelhança de Bakhtin (2003), "[...] gênero de texto como tipos relativamente estáveis de enunciados, elaborados sócio-historicamente, por diferentes esferas das atividades humanas, sempre apresentando conteúdo, estruturação, relação entre os interlocutores e estilo específicos".

O estudo realizado por Bronckart e seu grupo popularizou, ao menos em solo brasileiro, especialmente no escolar, o conceito de gênero de texto (ou gênero textual) dada a adoção das reflexões metodológicas empreendidas por seu grupo - para o trabalho com gêneros no espaço escolar através das chamadas "sequências didáticas" (DOLZ; NOVERRAZ; SCHNEUWLY, 2004). Tal noção foi amplamente utilizada nas reflexões apresentadas pelos "Parâmetros Curriculares Nacionais" (BRASIL, 1998) aos professores da educação básica, conforme diferentes estudos permitem verificar (e.g. BARROS; RIOSREGISTRO, 2014; PEREIRA, 2010).

No cerne dessa proposta está a releitura de Schneuwly e Dolz (2004) do conceito bakhtiniano de gênero. De base fortemente vigotskiana, a releitura dos autores do conceito de gênero do discurso propõe o conceito de gênero enquanto (mega)instrumento didático. $\mathrm{Na}$ proposição dos autores, no trabalho de ensino, o gênero assume tanto o papel de instrumento a comunicar quanto de objeto de ensino. Essa dupla articulação do gênero é que permite que ele funcione, também, como instrumento de desenvolvimento, tanto na dimensão do ensino quanto da formação continuada de professores. Expliquemos.

A compreensão de que, na teoria vigotskiana, "[...] o objeto do instrumento psicológico não está no mundo exterior, mas na atividade psíquica do sujeito, sendo esse instrumento um meio de influência do sujeito sobre si mesmo, um meio de autorregulação e autocontrole" (FRIEDRICH, 2012, p. 57), permite-nos entender que o conceito de gênero de texto enquanto instrumento pode auxiliar o sujeito a realizar os fenômenos psíquicos necessários para desenvolver uma determinada tarefa ( $\mathrm{e}, \mathrm{com}$ isso, promover o desenvolvimento das capacidades necessárias para esse agir). Isso porque o conceito de gênero (e os próprios gêneros) de texto compreende $(m)$ as três características elencadas por Vigotski para definir um instrumento psicológico: "1) é uma adaptação artificial; 2) tem 
uma natureza não orgânica, ou, em outras palavras, tem uma natureza social, e 3) é destinado ao controle dos próprios comportamentos psíquicos e dos outros" (FRIEDRICH, 2012, p. 58).

Nessa perspectiva, a compreensão de que o professor, quando internaliza o conceito de gênero de texto está contribuindo tanto para o seu desenvolvimento individual, pessoal, quanto para o da sua profissionalidade, reforça a hipótese de que o trabalho do professor não depende apenas de regulações externas (prescrições, como os documentos oficiais, por exemplo), mas também de modos de fazer que são próprios de cada trabalhador e do jeito com que eles se relacionam com o/apropriam-se do conhecimento necessário para a realização de tarefas no curso de seu agir (autoprescrições/prefigurações). Essa hipótese fica também melhor elucidada quando consideramos, assim como Machado e Lousada (2010, p. 626), que o processo de internalização (ou de transformação de um artefato ${ }^{1}$ em um instrumento psicológico) é sempre situado, realizado de acordo com o momento sóciohistórico, as intenções, capacidades e necessidades do sujeito. Quando se pensa sob a ótica do trabalho do professor, de sua profissionalidade e de seu desenvolvimento, poder-se-ia afirmar que:

[...] não se trata de simplesmente utilizar o artefato como mandam as prescrições, mas de usá-lo de modo que ele seja útil para o próprio trabalhador e adaptado por ele mesmo às diferentes situações em que precisa utilizá-lo. Assim, é só quando algum artefato é apropriado pelo sujeito que ele passa a ser verdadeiro instrumento psicológico, na concepção da teoria vigotskiana. Trata-se, portanto, de uma construção psíquica, que permite o desenvolvimento de diferentes capacidades. Em relação aos gêneros, eles só poderão servir de mediadores para a comunicação e para o desenvolvimento linguageiro se forem apropriados pelo sujeito. (MACHADO; LOUSADA, 2010, p. 626).

Ao que nos parece, é intrínseca à atividade docente a necessidade de apropriação de inúmeros gêneros de texto (enquanto instrumentos psicológicos) e de práticas sociais de

\footnotetext{
$1 \mathrm{Na}$ concepção das autoras, artefatos "[...] são 'objetos' materiais ou simbólicos, sócio-historicamente construídos para mediarem a ação do homem sobre o meio ou sobre o outro e para se atingirem determinadas finalidades. Entretanto, nenhum artefato, em si mesmo, pode servir como esse elemento mediador da ação humana". (MACHADO; LOUSADA, 2010, p. 625). Assim, embora os artefatos possam estar à disposição do trabalhador, eles, por si só, não bastam para a realização da tarefa e o desenvolvimento do sujeito. É preciso que ocorra a apropriação, por si e para si, do artefato, para que possa ocorrer o desenvolvimento. Em Friedrich (2012), a discussão ocorre no âmbito da transformação de instrumento (encarado, nesse contexto, como sinônimo de artefato) em instrumento psicológico. É esta última concepção que adotamos neste artigo.
} 
referência para que a transformação do trabalho (auto)prescrito/prefigurado em trabalho real na acepção bronckartiana - seja bem-sucedida. Sendo o trabalho do professor altamente orientado pela utilização de diferentes instrumentos, é na reelaboração desses instrumentos em suas práticas cotidianas de trabalho e formação que acreditamos poder ter acesso a índices que demonstrem a ocorrência (ou não) de seu desenvolvimento profissional. Nesse sentido, a mediação linguística que leva à transformação de diferentes artefatos em instrumentos psicológicos que propiciam o desenvolvimento do professor assume, para nós, papel nodal na compreensão do trabalho do professor.

A grande ênfase dispensada ao papel da linguagem no desenvolvimento (psíquico) humano é que caracteriza a vertente de pesquisas e análises do ISD. A compreensão de que um agir linguageiro se constrói pelo confrontamento das diferentes representações e compreensões engendradas pelos textos que os actantes produzem ao interatuarem em situações de (inter)ação social também funciona como justificativa e possibilidade de análise do desenvolvimento docente. Apesar de não ser possível ter acesso direto à ação do ponto de vista psicológico, as interpretações da ação são possíveis a partir das e nas produções verbais realizadas pelos sujeitos.

\section{Sobre a noção de desenvolvimento profissional: alguns apontamentos}

Neste artigo, importa-nos focalizar a relação entre linguagem e desenvolvimento profissional. Isso porque, é a partir das significações da linguagem, contextualizadas e de ordem sociocultural, das quais o sujeito se apropria, que o seu desenvolvimento pode ser potencializado. A formação continuada de professores e a apropriação de conceitos científicos e sua posterior transformação em instrumento psicológico nesse cenário podem ser relacionados a esse movimento que auxilia o sujeito a forjar novas significações sobre o mundo e sobre as ações que nele o sujeito realiza. Mas como podemos explicitar essa relação entre linguagem e desenvolvimento?

É verdade que a relação entre conhecimento e desenvolvimento está intimamente ligada à questão do psiquismo (ou de consciência, como alguns momentos da obra de Vigotski permitem perceber, de acordo com Friedrich, 2012, p. 47). Isso porque o psiquismo humano funciona como um "filtro" que seleciona certos elementos estáveis da realidade e transforma de modo que seja possível agir a partir disso. O psiquismo, assim, não 
representa fielmente o mundo, mas, antes disso, "trabalha o mundo" (FRIEDRICH, 2012, p. 49). Nesse sentido, ele distorce subjetivamente a realidade em favor do organismo. Mas como a formação continuada e um conceito científico podem intervir na ação do psiquismo? Como essas ações podem impulsionar o desenvolvimento profissional de professores?

É preciso lembrar que isso não se dá de um modo direto. É somente de um modo mediatizado, por meio de conceitos, de reconstruções, que a produção de conhecimento é possível e passível de motivar desenvolvimento. Da mesma forma, Vigotski (2009) descreve a relação entre a atividade de trabalho e a questão do emprego de ferramentas (que podem ser entendidas, aqui, como instrumentos) do seguinte modo:

[...] não podemos explicar satisfatoriamente o trabalho como atividade humana voltada para um fim, afirmando que ele é desencadeado por objetivos, por tarefas que se encontram diante do homem; devemos explicalo com o auxílio do emprego de ferramentas, da aplicação de meios originais sem os quais o trabalho não poderia surgir; de igual maneira, para a explicação de todas as formas superiores de comportamento humano, a questão central é a dos meios através dos quais o homem domina o processo do próprio comportamento (VIGOTSKI, 2009, p. 161).

A teoria vigotskiana permite que a noção de instrumento psicológico seja considerada como ferramenta, pois transforma o vínculo entre o instrumento (o conceito de gênero de texto, em nosso caso) e o processo psíquico necessário para resolver a tarefa (tomada de consciência sobre o conceito a fim de falar/escrever sobre/a partir dele ao produzir um PDG). E é na observação do emprego do instrumento psicológico, espontaneamente mobilizado pelo sujeito na e para a realização de determinada tarefa que podemos observar traços de sua transformação. A grande diferença entre instrumento e instrumento psicológico, nesse caso, está no fato de que "o objeto do instrumento psicológico não está no mundo exterior, mas na atividade psíquica do sujeito, sendo esse instrumento um meio de influência do sujeito sobre si mesmo, um meio de autorregulação e autocontrole" (FRIEDRICH, 2012, p. 57).

O que precisa ser lembrado aqui é que a função dos instrumentos psicológicos é estritamente artificial e age sobre os processos psíquicos, que são naturais. E é o controle artificial dos processos psíquicos com o auxílio de instrumentos psicológicos que se caracteriza como a essência do processo de desenvolvimento para Vigotski, de acordo com Friedrich (2012, p. 63). Talvez o momento exato dessa transformação do conceito em 
instrumento psicológico não possa ser apreendido na ocasião de sua ocorrência. No caso que nos interessa, o do desenvolvimento de professores, sua apreensão foi pensada a partir da escrita do professor, que pode denotar índices de influência, autorregulação ou autocontrole por parte da docente em formação continuada e desenvolvimento profissional cuja escrita praxiológica é, em parte, neste texto analisada.

Desse modo, buscamos, com esta pesquisa, contribuir para a área de estudos ao desvelar, mais especificamente, como o conceito de gênero de texto é internalizado pelo professor em formação continuada e é reconfigurado em seu agir, especificamente em sua dimensão praxiológica, passando de elemento externo de seu agir a elemento "interno" que orienta a sua própria ação. Para isso, valemo-nos do seu planejamento de um projeto didático de gênero - PDG - produzido pela professora Isadora ${ }^{2}$, a partir do qual focalizamos a emergência e tratamento didático do conceito de gênero de texto em sua escrita praxiológica.

\section{Os procedimentos de análise dos dados}

No âmbito da escrita de trabalho, selecionamos uma escrita em particular: o planejamento de um projeto didático de gênero - PDG - (GUIMARÃES; KERSCH, 2012; 2014; 2015) ${ }^{3}$ de uma professora que participou de um curso de formação continuada sobre a elaboração desse dispositivo didático entre os anos de 2012 a 2014.

Dada a complexidade do objeto de investigação, optamos por organizar essa categoria de análise em duas subdimensões, cada uma focalizando um aspecto da abordagem da noção de gênero na escrita do professor. A primeira subdimensão focaliza, como já anunciado, a abordagem do conceito de gênero de texto a partir de sua transposição didática e é nela que nos deteremos neste texto. Para isso, valemo-nos da discussão de Reuter (2013), nos termos

\footnotetext{
${ }^{2}$ Nome fictício atribuído à colaboradora da pesquisa. Isadora foi professora de Língua Portuguesa da rede municipal de ensino de Novo Hamburgo (RS), e participou da formação continuada que sustentou a geração dos dados desta pesquisa entre os anos de 2012 e 2014.

3 "Um Projeto Didático de Gênero é uma proposta metodológica de didatização de gêneros. Traz como diferencial o fato de ser um projeto, voltado, portanto, para uma sequência de atividades que se realizarão dentro e fora da escola, de forma a garantir que o(s) gênero(s) tratado(s) esteja(m) realmente ligados a uma prática social. Tal prática pode se dar no próprio âmbito da escola (o texto será publicado no jornal, no blog da escola, como pôster na parede, ou servirá para levar ao diretor/coordenador uma reivindicação dos alunos, etc.), como pode ir para além dos muros da escola. Neste caso, alia-se a práticas comunitárias (temáticas que dizem respeito ao local onde se localiza a escola: reivindicações do bairro, coleta seletiva de lixo, etc.) ou a práticas profissionais (como inscrever-se para um concurso/emprego; carta de recomendação, o que é isto; carta de apresentação para um emprego; curriculum vitae) e até a práticas políticas (debates, encaminhamento de reivindicações, conversa com autoridades)" (GUIMARÃES, 2014).
} 
das categorias de descrição dos gêneros de texto em uma perspectiva didática por ele propostas, fazendo uma relação com elementos da análise proposta por Bronckart (1999, 2006). Essa subdimensão tem como objetivo trazer à tona a (re)configuração da abordagem do conceito de gênero de texto em um PDG sobre o gênero carta de solicitação elaborado pela professora Isadora durante o ano de 2013. De viés eminentemente descritivo, esse movimento de análise pretende desvelar o(s) modo(s) como a professora colaboradora trata o conceito de gênero na materialidade da transposição didática. Trata-se de colocar em cena a face mais visível da abordagem do conceito de gênero de texto no trabalho do professor e formação continuada: a prefiguração do seu trabalho de ensino.

A seguir apresentamos um quadro-síntese das subdimensões de análise (Quadro 1) e explicamos mais detalhadamente os critérios que serão considerados em nossas análises.

Quadro 1 - As subdimensões de análise

\begin{tabular}{|c|c|}
\hline \multirow{11}{*}{$\begin{array}{l}\text { Abordagem do conceito de } \\
\text { gênero de texto a partir de } \\
\text { sua transposição didática }{ }^{4}\end{array}$} & Critérios norteadores: \\
\hline & $\begin{array}{l}\text { Designações em circulação do gênero escolhido e } \\
\text { eventuais conflitos terminológicos (ex.: narrativa de } \\
\text { detetive x narrativa de enigma). }\end{array}$ \\
\hline & $\begin{array}{l}\text { Conteúdos específicos a serem veiculados pelo gênero } \\
\text { escolhido. }\end{array}$ \\
\hline & A organização do gênero. \\
\hline & A arquitetura textual abordada (ex.: marcas gráficas). \\
\hline & Modos de inscrição material (ex.: suporte utilizado). \\
\hline & Características enunciativas. \\
\hline & $\begin{array}{l}\text { Tipologias e formas de articulação são observadas (ex.: } \\
\text { tipos de discurso, sequências discursivas e suas } \\
\text { articulações). }\end{array}$ \\
\hline & Sistemas semióticos abordados (ex.: verbal, icônico, sonoro). \\
\hline & $\begin{array}{l}\text { Formas sintáticas mais marcantes (ex.: discurso direto, } \\
\text { discurso indireto, conectores). }\end{array}$ \\
\hline & Unidades lexicais (ex.: léxico apropriado ao gênero). \\
\hline
\end{tabular}

Fonte: Elaborado pelo autor.

\footnotetext{
4 Essa seção do quadro apresentado foi inspirada pelo trabalho de Reuter (2013) sobre o estatuto e uso da noção de gênero de texto em didática, mas adaptado para a análise da arquitetura textual tal qual proposta por Bronckart $(1999,2006)$.
} 
Na primeira dimensão, buscaremos desvelar os modos como a escrita do professor nos permite observar índices de apropriação do conceito de gênero de texto e sua relação com a atividade prática de elaborar projetos didáticos de gênero, através de uma transposição didática do conceito de gênero de texto. Assim, o conceito deixa de ser meramente um objeto conceptual de formação e passa, como se espera, a ser um instrumento que orienta a ação/escrita do professor. É sobre essa dimensão que nos deteremos a seguir.

\section{Isadora e a transposição didática do gênero "carta de solicitação": pistas de (seu) desenvolvimento profissional}

Procurando trabalhar com questões relacionadas ao domínio do argumentar ${ }^{5}$, Isadora encontrou na "carta de solicitação" a possibilidade de desenvolver com seus alunos a construção de um posicionamento acerca do problema que encontraram em seu contexto social, Isadora, a partir da modelização didática do gênero (PIETRO; SCHNEUWLY, 2014, AUTOR \& OUTRO, 2015), que realiza, seleciona elementos que considerou relevantes no trabalho com o gênero. Em linhas gerais, seu modelo didático abordou elementos textuais do gênero (presença de argumentos convincentes, objetividade, consistência argumentativa, clareza na exposição de ideias), linguísticos (uso da norma culta, emprego adequado de pronomes), estruturais (local e data, identificação do destinatário, vocativo, sequencialidade textual - apresentação da problemática, argumentos que justifiquem a solicitação - expressão de despedida, assinatura e identificação do remetente). Ainda, em sua modelização didática, Isadora chamou a atenção para o fato de que cartas sociais e cartas de solicitação têm um elemento distintivo muito importante: a formalidade, pois saudações pessoais, expressões acaloradas ou demonstrações de sentimentos características das primeiras não pertencem ao gênero escolhido. Sua modelização sinaliza para uma preocupação com o estilo do gênero, para além das preocupações demonstradas por Isadora com a estrutura composicional e o conteúdo temático (BRONCKART, 1999). Nota-se, ainda que preliminarmente, que a professora manipulou de maneira adequada o conceito de

\footnotetext{
5 Para melhor caracterização deste domínio, no escopo da formação continuada que embasa esta pesquisa, é interessante ver Kersch (2014).
} 
gênero de texto ao qual foi exposta durante a formação continuada na escrita de sua modelização didática, ao apresentar, de modo consistente, elementos que remetam à clássica conceitualização do conceito de gênero, os quais, na definição bronckartiana, sinalizam para a estrutura composicional, o estilo e o conteúdo temático como aspectos característicos e definidores de um gênero de texto (a partir de sua análise linguísticotextual). A questão da interlocução, fortemente enfatizada na formação continuada de que ela fez parte, também é amplamente considerada por Isadora. Isso pode ser exemplificado pelo seguinte excerto extraído de sua modelização didática:

Nas cartas de solicitação, os argumentos apresentados devem estar calcados em bases sólidas, em ideias que realmente farão a diferença no momento de convencer o interlocutor, fazendo-o ter a noção exata de que o problema apresentado carece de um olhar cuidadoso. Somente assim a possibilidade de retorno poderá ser efetivada (ISADORA, 2014).

A seguir, ocupamo-nos a analisar mais detidamente o PDG de Isadora, procurando evidenciar índices, na transposição didática que realiza, de seu desenvolvimento profissional a partir da internalização do conceito de gênero de texto e sua transformação em instrumento psicológico que orienta seu agir (didático).

\subsection{A Escrita/Prefiguração do PDG "O Lixo que Transforma Vidas"}

Para dar conta do trabalho didático com o gênero em evidência em seu PDG, Isadora planejou 10 oficinas, além da aula dedicada à produção inicial das cartas de solicitação de doação. Sinteticamente, e respeitando os nomes dados pela própria professora às oficinas, apresentaremos cada uma delas, inserindo, naquelas cujo conteúdo seja diretamente relacionado ao trabalho com a transposição didática do conceito de gênero de texto, algumas asserções analíticas orientadas pelas categorias de abordagem do conceito de gênero de texto, conforme categorias de análise que apresentamos anteriormente. 


\section{- Oficina 1: Conhecer para convencer}

Nesta oficina a professora preocupou-se em evidenciar a necessidade de conhecer o assunto/tema para poder argumentar sobre ele. Assim, apresentou como pontos norteadores as seguintes questões:

a) qual é o principal material descartado em ambientes escolares? Qual a porcentagem de seu descarte?

b) organize uma tabela mostrando quais são os principais dejetos produzidos em uma escola e se possível as percentagens de cada um.

Como se pode notar, nesta primeira oficina, a professora (pre)ocupou-se em construir, com os alunos, o levantamento de informações relativas ao tema a ser desenvolvido na produção da carta de solicitação de doação. Houve uma preocupação sistemática com a geração e coleta de informações que possibilitem ao(s) aluno(s) terem domínio do assunto sobre o qual escreverão ao longo do PDG.

\section{- Oficina 2: Um olhar mais detalhado sobre o lixo que produzimos}

A preocupação com o conteúdo a ser abordado no PDG aparece de maneira saliente nesta oficina. A preparação de argumentos ligados ao tema denota a busca da professora em desenvolver, nos alunos, competências argumentativas que podem ser empregadas, inclusive, em outros gêneros do domínio do argumentar, não apenas neste em estudo. As perguntas norteadoras da oficina nos permitem observar isso:

a) qual é o tipo de material que é mais descartado nesse ambiente? [a professora refere-se aos demais ambientes escolares visitados pelos alunos, como a secretaria, laboratórios, cozinha, sala dos professores, banheiros e áreas externas]

b) você consegue explicar por que este material é o mais descartado aqui neste ambiente?

c) o que você pode fazer para diminuir o descarte desse material? (ISADORA, 2014).

Nesta oficina a professora Isadora expandiu os limites da sua atividade para além da sala de aula. Ao envolver outros ambientes escolares na pesquisa realizada pelos alunos, possibilitou que as demais pessoas que têm envolvimento no descarte de resíduos fossem sensibilizadas pela atividade por ela proposta. Isso favoreceu o engajamento dos alunos na 
reflexão e produção de ações que sinalizem para a construção da cidadania, assim como facilita a produção de argumentos.

\section{- Oficina 3: Quantas lixeiras serão necessárias?}

Esta oficina teve um acentuado trabalho com a argumentação. Os alunos, através de pesquisas e visitas ao pátio escolar, deveriam estimar quantas lixeiras seriam necessárias para comportar o descarte adequado de lixo da escola. Esses dados, segundo a professora Isadora, seriam essenciais para o êxito do projeto: convencer a empresa parceira do meio ambiente a doar a quantidade necessária de lixeiras à escola. Mas, além dessa argumentação no gênero carta de solicitação de doação, outro movimento de persuasão ocorreu internamente na sala de aula: dada a discordância dos alunos em relação ao número adequado de lixeiras, um debate oral foi realizado pela turma para chegar a um consenso sobre qual quantidade de lixeiras seria realmente necessária ao contexto escolar. Embora o gênero debate oral não seja alvo de nossas análises, foi importante sua ocorrência, pois acreditamos que ele contribuiu para a produção da carta de solicitação de doação ao tornar mais claro para os aprendizes um conteúdo importante do texto a ser produzido: o número de lixeiras deveria ser precisamente demonstrado na carta de solicitação de doação.

\section{- Oficina 4: Cara a cara com o gênero}

A partir desta oficina, fortemente influenciada pelos saberes que Isadora foi exposta durante a formação continuada, temos um claro movimento de transposição didática do conceito de gênero de texto em termos de organização do gênero e abordagem de sua arquitetura interna, como o próprio nome da oficina sugere. Nesta oficina, a professora Isadora dividiu os alunos em grupos e distribuiu diferentes exemplos de cartas de solicitação. Os alunos, em seus grupos, deveriam ler as cartas e observar atentamente sua estrutura. Posteriormente, deveriam anotar o que consideravam serem as principais características desse gênero de texto. Essa atividade demonstrou uma preocupação da professora em coconstruir com os alunos a caracterização da organização do gênero. A partir das observações dos alunos, a professora foi comparando as diferentes cartas lidas e características estruturais levantadas pelos alunos, sintetizando aquilo que todos consideravam serem elementos pertencentes à arquitetura interna do gênero e 
complementando as observações dos alunos, a partir da comparação com a modelização didática do gênero realizada por ela (descrita anteriormente).

\section{- Oficina 5: Que linguagem é essa?}

O trabalho com a análise dos exemplos de cartas de solicitação teve prosseguimento nesta oficina. Neste momento, o trabalho de transposição didática do conceito de gênero de texto feito pela professora Isadora focalizou mais diretamente questões linguísticas e textuais, no sentido mais estrito dos termos. Segundo seu planejamento, questões relacionadas à estrutura do gênero foram retomadas e aprofundadas, como se nota a seguir:

a) data, vocativo, corpo do texto e assinatura;

b) identificação do problema e suas causas;

c) exposição de argumentos que comprovem a necessidade de uma solução para o problema, vantagens que essa solução traria;

d) sugestões de possíveis medidas para a solução do problema;

e) agradecimentos sóbrios, assinatura;

f) linguagem formal, atenta às normas do padrão culto; rigor no emprego de pronomes de tratamento (ISADORA, 2014).

Observa-se, nesse momento da transposição didática de Isadora, uma imbricação do trabalho com questões de organização textual do gênero (data, exposição de argumentos, agradecimentos, assinatura etc.) com questões linguísticas no nível sintático e lexical, como apontado por Reuter (2013). As formas sintáticas (vocativos, neste caso) são observadas no trabalho com a construção da argumentação em função do seu uso, e não em termos de classificação sintática isolada, descontextualizada; da mesma forma que o trabalho com unidades lexicais que contribuem para a organização do gênero, como os pronomes de tratamento. Assim, a professora Isadora demonstra para seus alunos os modos de organização textual, sintática e lexical do gênero carta de solicitação a partir de seu uso na produção deste gênero.

\section{- Oficina 6: A produção do gênero}

Em grupos, os alunos foram convidados a produzirem uma carta de solicitação a partir dos conhecimentos já construídos nas oficinas anteriores. Essa versão do texto é que seria objeto de revisão e reescrita nas oficinas seguintes do PDG. Ainda nesta oficina, os grupos tiveram uma primeira atividade de hetero-revisão (BARBEIRO; PEREIRA, 2007), na 
qual os grupos trocaram suas cartas e comentaram as dos outros, de modo a contribuir para o desenvolvimento da textualidade de cada carta. A professora sinalizou, em relato analítico sobre este trabalho, o fato de que os alunos conseguiram perceber, com base nos conhecimentos construídos sobre argumentação, quais cartas possuíam argumentos inconsistentes ou "fracos" para os objetivos do projeto.

\section{- Oficina 7: Reescrevendo em grupo}

Considerando as ponderações feitas na hetero-revisão realizada na oficina anterior, os alunos foram convidados a reescreverem suas cartas nesta oficina. Após a revisão, das seis cartas escritas pela turma, duas seriam selecionadas, em votação, como mais adequadas ao gênero estudado e ao objetivo do projeto. Depois, na oficina seguinte, nova votação para escolher aquela que seria enviada à empresa. Nota-se, nesta oficina, uma preocupação didática da professora em tornar significativa a atividade de reescrita através da estratégia de votação nas cartas que melhor representem o objetivo do trabalho e fidelidade ao gênero estudado. Essa estratégia, ainda que não presente nas ponderações de Reuter (2013) sobre o trabalho didático com o gênero em si, agrega valor ao trabalho didático de Isadora, ao manter os alunos engajados na atividade.

\section{- Oficina 8: A escolha da carta e a produção final}

Esta oficina continuou o trabalho de reescrita da carta de solicitação de doação, a partir da escolha do texto da turma que serviria de base à carta que seria coletivamente assinada. Feita a votação a partir dos dois exemplares selecionados na oficina anterior, o trabalho da professora consistiu em, coletivamente, revisar a carta de solicitação de doação, pontuando, especialmente, aspectos como clareza na exposição do problema e dos argumentos. Concluída essa atividade, a carta de solicitação de doação foi enviada à empresa amiga do meio ambiente para quem seria solicitada a doação das lixeiras.

\section{- Oficina 9: Produção da grade de avaliação}

Um dos aspectos mais discutidos na formação continuada foi a avaliação do trabalho com gêneros de texto em um PDG. A estratégia indicada é, como já demonstrado no PDG de Isadora, a adoção de uma grade de avaliação que seja construída a partir dos elementos do 
gênero trabalhados nas oficinas do PDG, preferencialmente de maneira conjunta com os alunos $^{6}$. Essa grade desvela, em termos analíticos, uma questão muito interessante: além de sistematizar o que foi trabalhado, revela, de maneira pontual, aquilo que o professor considera essencial em termos de aprendizagem do gênero. Afinal, aquilo que é passível de avaliação é aquilo que se espera que tenha sido aprendido. A seguir, a grade de avaliação (Quadro 2) coconstruída por Isadora com seus alunos:

Quadro 2 - Grade de Avaliação PDG Carta de solicitação

\begin{tabular}{|l|l|l|l|}
\hline \multicolumn{1}{|c|}{ Aspectos a considerar } & Atingiu & Atingiu em parte & Não atingiu \\
\hline $\begin{array}{l}\text { A linguagem empregada está adequada ao } \\
\text { gênero? }\end{array}$ & & & \\
\hline O problema foi apresentado com clareza? & & & \\
\hline Os argumentos estão claros e convincentes? & & & \\
\hline $\begin{array}{l}\text { A estrutura do gênero foi respeitada e nenhuma } \\
\text { parte foi esquecida? }\end{array}$ & & & \\
\hline $\begin{array}{l}\text { Compreendi e consigo redigir uma carta de } \\
\text { solicitação? }\end{array}$ & & & \\
\hline
\end{tabular}

Fonte: Isadora (2014).

Na grade de avaliação apresentada, observamos a preocupação da professora em respeitar as capacidades de linguagem dos alunos de $5^{\circ}$ ano, pois não apresenta elementos complexos que estão além de sua capacidade de compreensão e avaliação nos itens sugeridos. Consoante Cerqueira e Martins (2013), Isadora foi capaz de, na mobilização de conceitos relacionados ao gênero, selecionar o que seria avaliado, considerando "i) conteúdos decorrentes da especificidade do texto em causa e ii) dificuldades diagnosticadas nos alunos". Assim, supera a tentação de, como professora de Língua Portuguesa, "corrigir tudo" ou trabalhar todos os aspectos possíveis do gênero.

Sobre a grade em si, os quatro primeiros itens da avaliação remetem, ainda que genericamente, para elementos de estrutura do gênero, de conteúdo temático e, por que não, de estilo, ao atentar para o uso adequado da linguagem. A apropriação do conceito de gênero de texto e sua abordagem praxiológica é que permitem à professora Isadora tratar

\footnotetext{
${ }^{6}$ Cabe salientar que movimentos de avaliação foram realizados antes mesmo da coconstrução da grade de avaliação do PDG pela professora com os alunos. Nas Oficinas 7 e 8 temos momentos em que foram realizadas avaliações da aprendizagem dos alunos, ainda que sem a grade apresentada nesta Oficina.
} 
de elementos intrínsecos ao conceito de gênero de texto de maneira adequada ao seu contexto de atuação, notadamente na perspectiva da transposição didática. Ao coconstruir com os alunos essa grade de avaliação, Isadora mobiliza saberes relacionados à didática da língua e ao conceito de gênero de texto, demonstrando, ainda que preliminarmente, uma transformação do conceito de gênero de texto em instrumento psicológico, que regula e controla o comportamento psíquico $(F R I E D R I C H, 2012)$ da professora e de seus alunos na atividade didática de avaliar a produção textual da carta de solicitação de doação. Isso se mostrará mais claramente na análise que faremos do artigo em que Isadora apresenta e discute esse trabalho com o gênero carta de solicitação. Isadora, entretanto, seguiu uma estratégia bastante "tradicional" ao usar a grade de avaliação, pois a empregou apenas no momento final de seu PDG, como forma de os alunos se autoavaliarem, e não como processo no seu trabalho de ensino.

\section{- Oficina 10: Avaliando o PDG e os conhecimentos construídos}

Esta última oficina do PDG da professora Isadora, ainda que não aborde especificamente nenhuma questão sobre o conceito de gênero de texto, cabe ser aqui descrita pelo seu caráter de sistematização e capitalização da aprendizagem dos alunos acerca da produção de uma carta de solicitação. O último item da grade de avaliação já sinalizava para isso e, nesse momento, Isadora voltou claramente ao trabalho realizado nas oficinas anteriores e discutiu com os alunos o significado das aprendizagens concebidas no PDG. Em relato sobre esta atividade, a professora salientou que muitos alunos afirmaram que o conhecimento que adquiriram neste PDG poderia ser empregado em outros contextos, nos quais, porventura, tivessem de redigir alguma solicitação. Ainda que não seja objeto de análise neste texto, a transformação do conceito de gênero de texto em instrumento psicológico também pode ter chegado aos alunos de Isadora, pois, a partir deste trabalho, também poderão, possivelmente, controlar, de maneira consciente, o seu trabalho com a linguagem em gêneros do domínio do argumentar, especialmente em cartas de solicitação de doação.

Encerrando movimento analítico, em que a subdimensão da transposição didática do conceito de gênero em um PDG foi evidenciada, podemos constatar que boa parte dos aspectos elencados por Reuter (2013) para o trabalho didático com gêneros de 
texto foram apreendidos no trabalho de Isadora. A eventual incompletude da transposição didática e do trabalho com o conceito de gênero de texto, quando se considera o ideal em termos de escrita do planejamento didático, pode ser relativizado quando se considera que essa "vigilância epistemológica" em torno do conceito de gênero de texto não costuma fazer parte da escrita profissional de professores quando do planejamento de seus PDGs.

Diante do que vimos na análise da transposição didática de Isadora, podemos sinalizar, preliminarmente, para a existência de uma reconfiguração do conceito de gênero de texto que se dá na elaboração de um PDG. Essa reconfiguração indicia a transformação do conceito em instrumento psicológico para agir, mas também desvela a possibilidade de encontrar nas práticas didáticas de professores objetos de saber e elementos para a/da construção do conhecimento sobre o seu trabalho de ensino.

\section{Considerações finais}

Quando Isadora tomou para si o conceito de gênero de texto e o reconfigurou em seu agir praxiológico, a partir do trabalho com PDG, notamos uma influência sobre o seu agir, evidenciando a transformação do conceito de gênero de texto em instrumento psicológico. Para reforçar essa consideração, podemos relembrar de sua modelização didática, que permite a ela elencar os elementos "ensináveis" do gênero. Ou seja: é um agir sobre si mesma ao prefigurar seu trabalho de ensino.

Se o conceito de gênero de texto assume caráter de prefiguração do agir didático de Isadora, de algum modo ele também permite à professora autorregular seu trabalho, característica essa inerente a um instrumento psicológico. Nos dados analisados isso fica evidente quando Isadora produz com seus alunos a grade de avaliação do PDG, em que aspectos essenciais do conceito de gênero de texto (e de trabalho com gêneros de texto) vêm à tona. Ou seja: para que cumprisse seu papel e seu planejamento, para que "atingisse seu objetivo" enquanto professora, o domínio do conceito de gênero de texto exerce um papel autorregulador: a partir da sua compreensão do conceito (e conhecimento do exemplar de gênero a ser trabalhado) é que Isadora e seus alunos caminhariam para chegar até o objetivo proposto. 
Ecoando Friedrich (2012), é válido lembrar que a transformação de um conceito em instrumento psicológico permite ao homem agir sobre seu próprio comportamento psíquico a fim de produzir um efeito desejado, do qual se é o objeto. Na transformação do conceito de gênero de texto em instrumento psicológico, Isadora se vale da função mediatizante do conceito para exercer, também, autocontrole sobre si mesma. A internalização do conceito permite a Isadora prefigurar e regular as aprendizagens que seus alunos farão ao longo do seu PDG. Como seu trabalho a partir desse dispositivo de ensino não ocorria até 2012, não é demais afirmar que temos, aí, evidências de que seu desenvolvimento profissional ocorreu a partir da formação continuada de que ela participou.

Por fim, vale ressaltar que a apreensão do conceito de gênero na escrita da professora participante dessa pesquisa versus a apreensão de um conceito do gênero (empregado no PDG) muitas vezes não é clara, imprimindo ao percurso investigativo contingências que se marcam nas análises realizadas. Vale, portanto, o desafio de seguir investigando evidências do desenvolvimento profissional de professores para, quem sabe, munidos desse conhecimento, podermos avançar na(s) estratégia(s) de formação docente.

\section{Referências}

AMIGUES, R. Trabalho do professor e trabalho de ensino. In: MACHADO, A. R. (Org.). $O$ ensino como trabalho: uma abordagem discursiva. Londrina: Eduel, 2004. p. 35-54.

BAKHTIN, M. Estética da criação verbal. 4. ed. São Paulo: Martins Fontes, 2003.

BARBEIRO, L. F.; PEREIRA, L. Á. O ensino da escrita: a dimensão textual. Lisboa: Ministério da Educação, Direcção-Geral de Inovação e de Desenvolvimento Curricular, 2007.

BARROS, E. M. D.; RIOS-REGISTRO, E. S. (Org.) Experiências com sequências didáticas de gêneros textuais. Campinas: Pontes, 2014.

BRASIL. Ministério da Educação e Cultura. Secretaria da Educação Básica. Parâmetros Curriculares Nacionais: Língua Portuguesa. 3. ed. Brasília, DF, 1998.

BRONCKART, J. P. Atividade de linguagem, discurso e desenvolvimento humano. Campinas: Mercado de Letras, 2006.

BRONCKART, J. P. Atividade de linguagem, textos e discursos: por um interacionismo sóciodiscursivo. São Paulo: EDUC, 1999. 
BRONCKART, J. P. Atividade de linguagem, textos e discursos: por um interacionismo sóciodiscursivo. São Paulo: EDUC, 1999.

BRONCKART, J. P. Le rôle de la maîtrise du langage dans le développement psychologique humain. Nonada: Letras em revista, Porto Alegre, ano 14, n. 17, p. 11-36, 2011.

BRONCKART, J. P. O agir nos discursos. Campinas: Mercado de Letras, 2008.

BRONCKART, J. P. Um retorno necessário à questão do desenvolvimento. In: BUENO, L.; LOPES, M. A. T.; CIRISTÓVÃO, V. L. (Org.) Gêneros textuais e formação inicial: uma homenagem à Malu Matêncio. Campinas: Mercado de Letras, 2013. p. 85-107.

CERQUEIRA, A.; MARTINS, B. (Trans)formar práticas de ensino da escrita: autorreflexão e erro. In: PEREIRA, L. Á.; CARDOSO, I. (Coord.). Reflexão sobre a escrita: o ensino de diferentes géneros de textos. Aveiro: Editora da Universidade de Aveiro, 2013. p. 145-180.

DOLZ, J.; NOVERRAZ, M.; SCHNEUWLY, B. Sequências didáticas para o oral e a escrita: apresentação de um procedimento. In: DOLZ, J.; SCHNEUWLY, B. Gêneros orais e escritos na escola. Campinas: Mercado de Letras, 2004. p. 95-128.

FRIEDRICH, J. Lev Vigotski: mediação, aprendizagem e desenvolvimento. Campinas: Mercado de Letras, 2012.

GUIMARÃES, A. M. M. Formação de professores: entre o acadêmico e o profissional. Palestra apresentada no $2^{\circ}$ Encontro Procad/Casadinho UFMG-UNISINOS, Belo Horizonte, 2014.

GUIMARÃES, A. M. M.; KERSCH, D. F. A caminho da construção de projetos didáticos de gênero. In: GUIMARÃES, A. M. M.; KERSCH, D. F. (Org.). Caminhos da construção: projetos didáticos de gêneros na sala de aula de língua portuguesa. Campinas: Mercado de Letras, 2012. p. 21-44.

GUIMARÃES, A. M. M.; KERSCH, D. F. E então... Caminhos da construção de projetos didáticos de gênero- da comunidade de indagação ao desenvolvimento de professoras(es) e das pesquisadoras. In: GUIMARÃES, A. M. M.; CARNIN, A.; KERSCH, D. F. (Org.). Caminhos da construção: reflexões sobre projetos didáticos de gênero. Campinas: Mercado de Letras, 2015, p. 7-26.

GUIMARÃES, A. M. M.; KERSCH, D. F.. Explorando os projetos didáticos de gênero como um caminho metodológico. In: GUIMARÃES, A. M. M.; KERSCH, D. F. (Org.). Caminhos da construção: projetos didáticos de gênero no domínio do argumentar. Campinas: Mercado de Letras, 2014, p. 17-38.

ISADORA. [Projeto didático de gênero Carta de solicitação]. São Leopoldo, 2014. Material didático produzido pela autora.

KERSCH, D. F. Sobre as dificuldades e desafios de se trabalhar com gêneros do domínio do argumentar. In: GUIMARÃES, A. M. M.; KERSCH, D. F. (Org.). Caminhos da construção: projetos didáticos de gênero no domínio do argumentar. Campinas: Mercado de Letras, 2014b. p. 51-71. 
MACHADO, A. R.; BRONCKART, J. P. (Re-)configurações do trabalho do professor construídas nos e pelos textos: a perspectiva metodológica do grupo ALTER-LAEL. In: ABREU-TARDELLI, L. S.; CRISTOVÃO, V. L. L. (Org.). Linguagem e educação: o trabalho do professor em uma nova perspectiva. Campinas: Mercado de Letras, 2009. p. 31-78.

MACHADO, A. R.; LOUSADA, E. G. A apropriação de gêneros textuais pelo professor: em direção ao desenvolvimento pessoal e à evolução do "métier". Linguagem em (Dis)curso, Palhoça, SC, v. 10, n. 3, p. 619-633, set./dez. 2010.

PEREIRA, R. C. M. Ações de linguagem e prática docente: desafios e avanços na formação continuada. In: PEREIRA, R. C. M. (Org.). Ações de linguagem: da formação continuada à sala de aula. João pessoa: Editora Universitária UFPB, 2010. p. 17-33.

PIETRO, J. F. de; SCHNEUWLY, B. O modelo didático de gênero: um conceito da engenharia didática. In: NASCIMENTO, E. L. (Org.). Gêneros textuais: da didática das línguas aos objetos de ensino. Campinas: Pontes, 2014. p. 51-81.

REUTER, Y. Statut et usages de la notion de genre en didactique(s): retour sur quelques propositions. Pratiques, Paris, n. 157/158, p. 153-164, juin. 2013.

SCHNEUWLY, B.; DOLZ, J. Gêneros orais e escritos na escola. Campinas: Mercado de Letras, 2004 .

VIGOTSKI, L. S. A construção do pensamento e da linguagem. São Paulo: Martins Fontes, 2009. Originalmente publicado em 1934.

\footnotetext{
i Anderson CARNIN, professor.

Unisinos/CNPq.

Doutor em Linguística Aplicada. Realiza, atualmente, estágio de pós-doutoramento na Unisinos, com bolsa PDJ-CNPq.
} 
